Vol. 19(2010): 184-192.

\title{
Model prediction of frost tolerance as related to winter survival of wheat in Finnish field trials
}

\author{
Anne Kari Bergjord*1,2, Helge Bonesmo ${ }^{1, \mathrm{a}}$ and Arne Oddvar Skjelvåg ${ }^{2}$ \\ ${ }^{I}$ Norwegian Institute for Agricultural and Environmental Research, Grassland and Landscape Division \\ Kvithamar,N-7500 Stjørdal,Norway,*email:anne.kari.bergjord@bioforsk.no \\ ${ }^{2}$ Norwegian University of Life Sciences, Department of Plant and Environmental Sciences, \\ Box 5003, N-1432 As, Norway \\ aPresent address: Norwegian Agricultural Economics Research Institute, Statens hus, \\ Prinsensgate 1, N-7468 Trondheim, Norway
}

\begin{abstract}
The model FROSTOL simulates course of frost tolerance in winter wheat on a daily basis from sowing on as affected by soil temperature $(2 \mathrm{~cm})$, snow cover, phenological development, and a genotypic maximum level of frost tolerance $\left(\mathrm{LT}_{50}\right)$. A series of cultivar trials in Finland was used to evaluate the model's ability to estimate plant survival in natural field environments during winters with differing weather conditions. Recorded survival was compared with number of intersections between the curves of simulated LT50 and the soil temperature curve for each field. A cumulative stress level (CSL) was calculated based both on number of intersections and FROSTOL simulated stress levels. The correlation between CSL and field recordings was quite low. While the field trials characterize a general ability to stand various types of winter stress, FROSTOL estimates damage caused by the soil temperature regime only. However, FROSTOL simulations seemed to correspond reasonably well to field observations when low temperature was the eventual cause of damage.
\end{abstract}

Key-words: winter wheat, frost tolerance, phenological development, ice cover, snow mould, winter survival.

\section{Introduction}

Among the numerous models simulating winter wheat performance in response to environmental factors (e.g. Semenov and Porter 1995, Rickman et al. 1996, Jamieson et al. 1998), the recently published
FROSTOL (Bergjord et al. 2008) is one of very few models that specifically aims at predicting winter survival of the crop. FROSTOL simulates course of frost tolerance, expressed as $\mathrm{LT}_{50}$ (the temperature at which $50 \%$ of the plant populations are killed), on a daily $(t)$ time step from sowing onwards as:

(C) Agricultural and Food Science

Manuscript received December 2008 
Vol. 19 (2010): 184-192.

$\mathrm{LT}_{50 \mathrm{t}}=\mathrm{LT}_{50 \mathrm{t}-1}-\mathrm{RH}+\mathrm{RD}+\mathrm{RS}+\mathrm{RR}$

Frost tolerance increases (lowering $\mathrm{LT}_{50}$ ) by hardening $(\mathrm{RH})$ and decreases by dehardening (RD) and stress. Two stress terms are included. One of them is caused by exposure to low temperature (RS). The other one is related to conditions where respiration stress might occur, conditions where the soil is unfrozen and the ground simultaneously covered with snow (RR). Plants in unfrozen soil would have a higher respiration rate than those in frozen soil, and a dense snow cover might, as ice encasement, create more or less anaerobic conditions for respiration and capture of metabolites like $\mathrm{CO}_{2}$, ethanol, and lactate (Andrews and Pomeroy 1979, Gudleifsson 1997).

The functional relationships of the model are all driven by daily measurements of soil temperature $(2 \mathrm{~cm})$. One of them (RR) is in addition affected by snow depth, and two (RH and RD) are conditioned by stage of phenological development. Several experiments have demonstrated a reduced ability to harden and an increased liability to dehardening once the plants are fully vernalized and induced to generative development (e.g. Fowler et al. 1996a, 1996b, Mahfoozi et al. 2001a, 2001b, Danyluk et al. 2003, Limin and Fowler 2006). In FROSTOL this is actuated by terminating the ability of the plants to further hardening, and lowering the temperature threshold for dehardening, after vernalization saturation. A more complete description of the model is given by Bergjord et al. (2008).

FROSTOL was optimized and calibrated by data from experiments where the winter wheat plants were grown outdoors in boxes. A cross validation of the model indicated that its parameters were satisfactorily insensitive to variation in winter weather (Bergjord et al. 2008). However, the model has not yet been tested by the use of independent data derived from common field management practices. The objective of the present study was to evaluate the model's ability to estimate plant survival or death in true field environments during winters with differing weather conditions.

\section{Material and methods}

The data used in the present study were recorded from a series of cultivar trials in Finland conducted at six sites in the years 1989/90, 1990/91, and 1991/92 (Hömmö 1994). The locations were: Mietoinen $\left(60^{\circ} 8^{\prime} \mathrm{N}, 21^{\circ} 51^{\prime} \mathrm{E}\right)$, Anjalankoski $\left(60^{\circ} 43^{\prime} \mathrm{N}\right.$, $\left.26^{\circ} 48^{\prime} \mathrm{E}\right)$, Jokioinen (6049'N, $\left.23^{\circ} 30^{\prime} \mathrm{E}\right)$, Pälkäne (61 $\left.{ }^{\circ} 20^{\prime} \mathrm{N}, 2^{\circ} 13^{\prime} \mathrm{E}\right)$, Laukaa (62 $\left.20^{\circ} \mathrm{N}, 26^{\circ} 10^{\prime} \mathrm{E}\right)$,

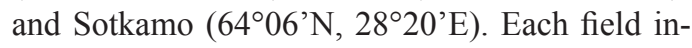
cluded 21 different cultivars covering a large range of variation in frost tolerance.

The fields were sown late August and fertilised in autumn according to the normal practice of the area. All cultivars were sown in $1 \mathrm{~m}$ rows, completely randomized, and in four replicates. Winter survival was rated by counting number of living plants both in autumn and in spring soon after snow melting. Further information about the field trials is given by Hömmö (1994).

Weather records including minimum, maximum and mean air temperature (1.5 $\mathrm{m}$ above ground), amount and form of precipitation, depth of snow cover, relative air humidity, and wind speed were provided for all locations by The Finnish Meteorological Institute, Helsinki. Unfortunately, no recordings of soil temperature in $0-5 \mathrm{~cm}$ depth were available, which is a necessary input to the FROSTOL model. To obtain estimates of the soil surface temperature on a daily basis, the Norwegian model SnowFrost (Thorsen and Haugen 2007) was applied. Input data for these simulations were diurnal mean air temperature and daily recordings of snow depth and precipitation for each location and year.

Maximum attainable frost tolerance level $\left(\mathrm{LT}_{50 \mathrm{c}}\right)$ of the different cultivars is required to run the FROSTOL model. Pulli et al. (1996) list results from several different methodological tests of frost tolerance for the cultivars included in the Finnish data set. The listed results from an Icelandic test applying a similar method as the one used in the development of FROSTOL were used to estimate an $\mathrm{LT}_{50 \mathrm{c}}$ for the different cultivars. The plants used in the Icelandic test had been hardened at $2{ }^{\circ} \mathrm{C}$ for two weeks only before they were tested. Thus, 
Bergjord, A. K. et al., Modelling frost tolerance and winter survival in winter wheat

their internal ranking was shown, but they had not reached their maximum attainable levels of frost tolerance after these two weeks of hardening. To estimate values of $\mathrm{LT}_{50 \mathrm{c}}$ of the applied cultivars, FROSTOL was run with a constant temperature of $2{ }^{\circ} \mathrm{C}$ combined with differing levels of $\mathrm{LT}_{50 \mathrm{c}}$ in order to develop a set of curves for the course of hardening (Fig. 1). Data on $\mathrm{LT}_{50}$ of each cultivar from the Icelandic test were then used to position the cultivars on one of the fitted curves at 14 days. As a result, the cultivars were grouped in five classes with values of $\mathrm{LT}_{50 \mathrm{c}}$ at $-12^{\circ} \mathrm{C}$ (four cultivars), -14 ${ }^{\circ} \mathrm{C}$ (eight cultivars), $-16{ }^{\circ} \mathrm{C}$ (three cultivars), -18 ${ }^{\circ} \mathrm{C}$ (four cultivars), and $-22{ }^{\circ} \mathrm{C}$ (two cultivars).

Hömmö (1994) grouped the cultivars somewhat differently; with a difference in ranking as expected. Hömmö's ranking was based on recorded mean winter survival, reflecting the cultivars' overall abilities to tolerate different kinds of abiotic and biotic winter stress, whereas the above mentioned ranking used in the present study is based on frost tolerance only.

Model simulations were run for each combination of year, location, and level of maximum frost tolerance. The model outputs were thereafter com- pared with recorded mean survival of the different cultivar classes. The more intersections found between the soil temperature curve and the curve of simulated $\mathrm{LT}_{50}$, the poorer survival of plants was expected. In order to account for these specific critical incidents, and also the impact of more long-term stressful conditions, a simulated cumulative stress level (CSL) throughout the winter was calculated and correlated with recorded survival for each year, location, and cultivar class. The equation of CSL (2) includes two kinds of stress simulated by FROSTOL (RR and RS), which both express daily impairments in $\mathrm{LT}_{50}$ due to low temperature and snow cover, respectively, and a factor related to number of incidents when the diurnal mean soil surface temperature got lower than the corresponding simulated $\mathrm{LT}_{50}$. This contribution was included simply by multiplying the total number of such incidents per simulation series by a constant, set to 0.05 . Thus, CSL during a winter of $\mathrm{n}$ days with $\mathrm{I}$ number of intersections was calculated as:

$$
\mathrm{CSL}=\Sigma_{i=1}^{n}(R R+R S)_{i}+0.05 \sum_{i=0}^{n} \mathrm{I}_{i}
$$

Fig. 1. Simulated course of $\mathrm{LT}_{50}$ at a constant temperature of $2{ }^{\circ} \mathrm{C}$ for cultivars with levels of maximum attainable frost tolerance ranging from -12 to $-22^{\circ} \mathrm{C}$.

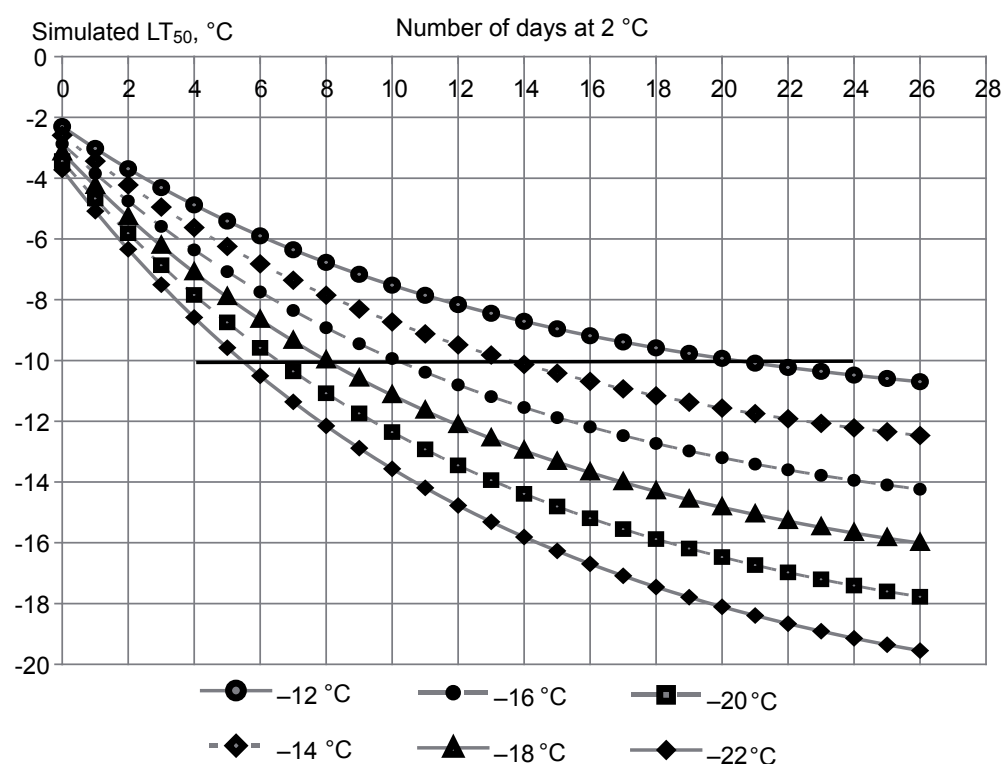


Vol. 19 (2010): 184-192.

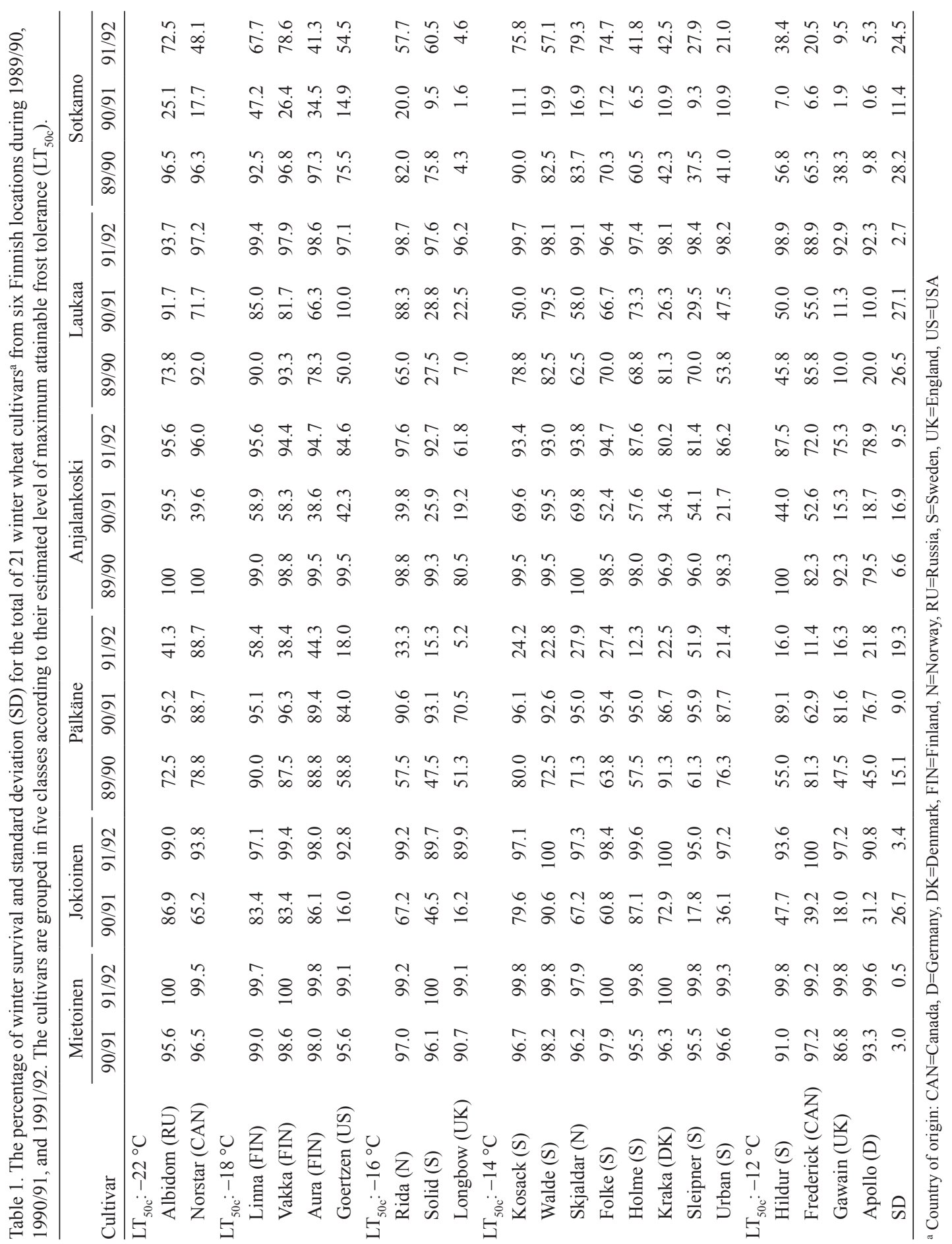


Bergjord, A. K. et al., Modelling frost tolerance and winter survival in winter wheat

\section{Results and discussion}

The Finnish data set used in this study comprises winters characterized by low temperatures and rather long periods with snow cover, as well as relatively mild winters with short cold spells (Fig. 2). Soil temperatures estimated by SnowFrost seemed reasonable. The temperature stayed at about $0{ }^{\circ} \mathrm{C}$ as long as the soil was covered by deep snow, while varying closer to the prevailing air temperature when snow cover was thin or absent (Fig. 2). Wheat winter survival varied considerably between years and locations (Table 1). In five cases, approximately no plant damage was seen in field at springtime (Mietoinen 1990/91 and 1991/92, Jokioinen 1991/92, Anjalankoski 1989/90, and Laukaa 1991/92). In the remaining fields, differential levels of winter damage were seen among cultivars. Some snow mould was observed in most of the fields, but the most damaging infections occurred in Laukaa 1990/91 and in Sotkamo 1990/91. In Pälkäne 1991/92 and Anjalankoski 1990/91 ice covered the fields unevenly and caused irregular winter survival of plants (Hömmö 1994). As FROSTOL does not account for stress and plant damage caused by snow mould infections and ice cover, these four fields were excluded from further analyses.

Figure 3 shows two selected examples from the Finnish field trials of the simulated course of $\mathrm{LT}_{50}$ for cultivar classes with differing $\mathrm{LT}_{50 \mathrm{c}}$ values. In cases where none of the curves of simulated $\mathrm{LT}_{50}$ were intersected by the soil temperature curve, no frost damage should be expected (Fig. 3A). As number of intersections between an $\mathrm{LT}_{50}$ curve and the temperature curve increased, percent surviving plants from the corresponding cultivar class was expected to decrease. Figure 3B shows an example of a field where cultivars with high frost tolerance $\left(\mathrm{LT}_{50 \mathrm{c}}\right.$ of -22 and $\left.-18{ }^{\circ} \mathrm{C}\right)$ had high levels of survival, while the recordings of cultivars with an $\mathrm{LT}_{50 \mathrm{c}}$ at $-12,-14$, and $-16^{\circ} \mathrm{C}$, were at 42.6 , 63.5 , and $54.0 \%$ surviving plants, respectively (see also Table 1). Comparison between the simulated $\mathrm{LT}_{50}$ curves of the different classes of cultivars and the soil surface temperature showed similar relations with an increasing number of intersections with decreasing frost tolerance (i.e. rising $\mathrm{LT}_{50 \mathrm{c}}$ temperature).

The close relationship between induction of generative development and decrease in frost tolerance provides the phenological module with a strong control of the last gain in frost tolerance during hardening. If the timing of generative induction is estimated too early, the ability of the plants to harden will be terminated too early as well, giving a higher risk of frost damage. Mietoinen 1990/91 and 91/92, and Jokioinen 1991/92 are possible examples of such a situation. According to the FROSTOL simulations for these fields there should have been reduced survival of the cultivars with the lowest frost tolerance. However, hardly any damage was recorded. The discrepancy can be explained by the lack of a photoperiodic factor in the FROSTOL module simulating phenological development. It has been shown that the induction of generative development may be delayed beyond vernalization saturation by the absence of long photoperiods (Slafer and Rawson 1996, Mahfoozi et al. 2001a, 2001b, Danyluk et al. 2003). An experiment performed by Bergjord et al. (2009) indicated that the induction, and consequently the reduced ability to gain and maintain a high level of frost tolerance, was delayed for about one month after vernalization saturation by the absence of long photoperiods. The amount of available data was, however, too scarce to develop a reliable functional relationship between photoperiod and the timing of generative induction in FROSTOL.

The effect on simulated course of frost tolerance of a delay in generative induction by 21 days after vernalization saturation is shown for Mietoinen 1991/92 in Figure 4. This delay gave the plants a longer hardening period and hence a higher level of frost tolerance. In this case, the attained increase in frost tolerance due to later induction of generative development was enough to avoid frost damages when the temperature dropped in early December.

The correlation between simulated CSL and recorded percent surviving plants was low $\left(\mathrm{R}^{2}=\right.$ 0.34 ), even when FROSTOL was run with a delay in generative induction by about 20 days after vernalization saturation. This low correlation can 


\section{AGRICULTURAL AND FOOD SCIENCE}

Vol. 19 (2010): 184-192.

Anjalankoski

Temperature, ${ }^{\circ} \mathrm{C} /$ Snow depth, $\mathrm{cm}$

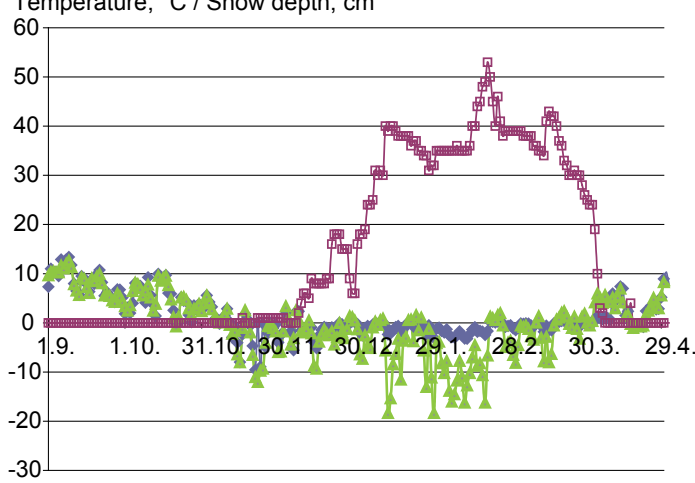

Jokioinen

Temperature, ${ }^{\circ} \mathrm{C} /$ Snow depth, $\mathrm{cm}$

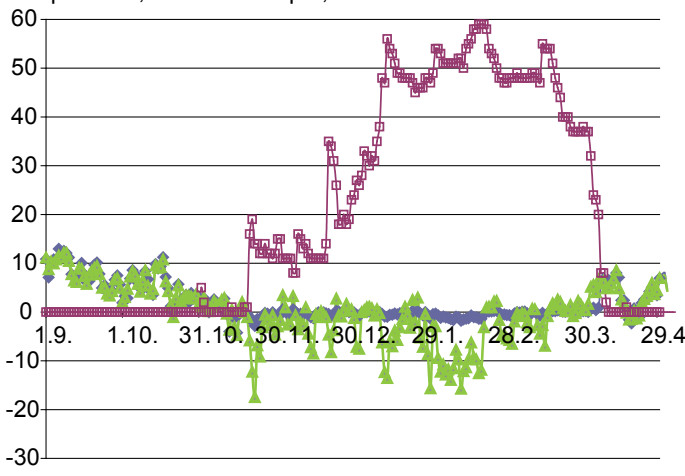

Laukaa

Temperature, ${ }^{\circ} \mathrm{C} /$ Snow depth, cm

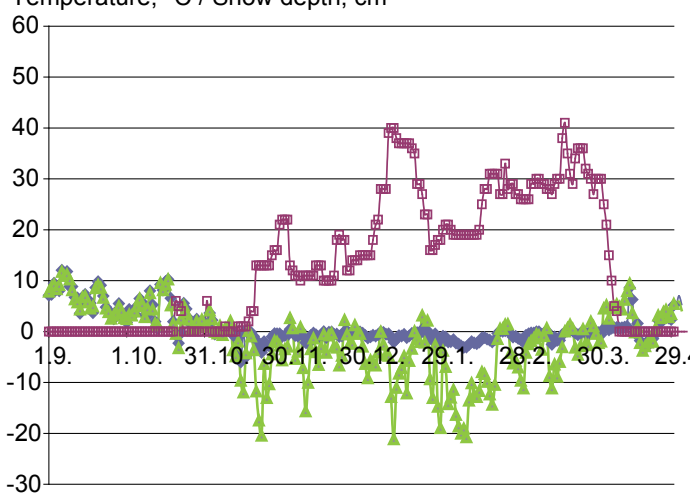

Mietoinen

Temperature, ${ }^{\circ} \mathrm{C} /$ Snow depth, $\mathrm{cm}$

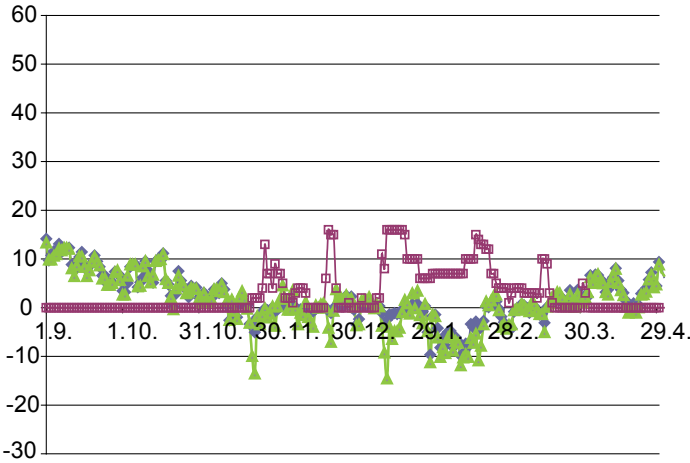

Pälkäne

Temperature, ${ }^{\circ} \mathrm{C} /$ Snow depth, cm

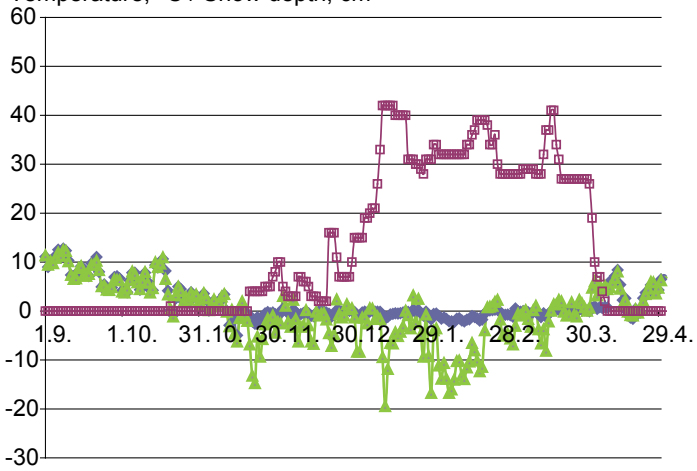

Sotkamo

Temperature, ${ }^{\circ} \mathrm{C} /$ Snow depth, $\mathrm{cm}$

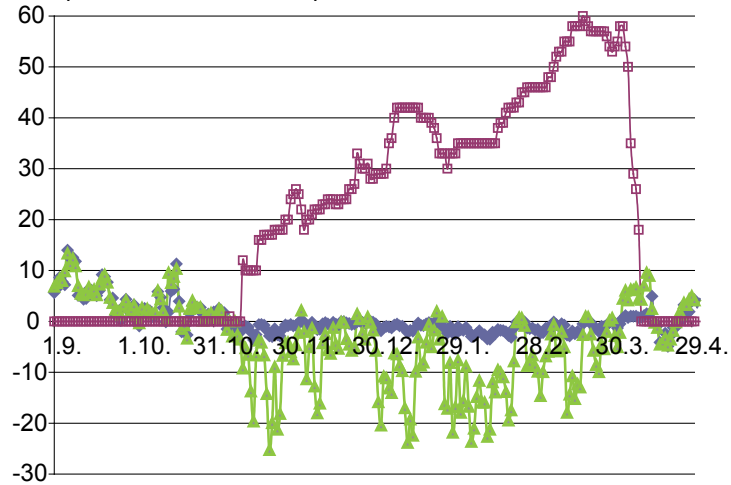

Soil temp

Air temp

$\square$ Snow

Fig. 2. Recorded air temperature and snow depth, and calculated soil surface temperature (SnowFrost, Thorsen and Haugen 2007) at six Finnish locations during the winter 1990/91. 
Bergjord, A. K. et al., Modelling frost tolerance and winter survival in winter wheat

Anjalankoski 1989/90

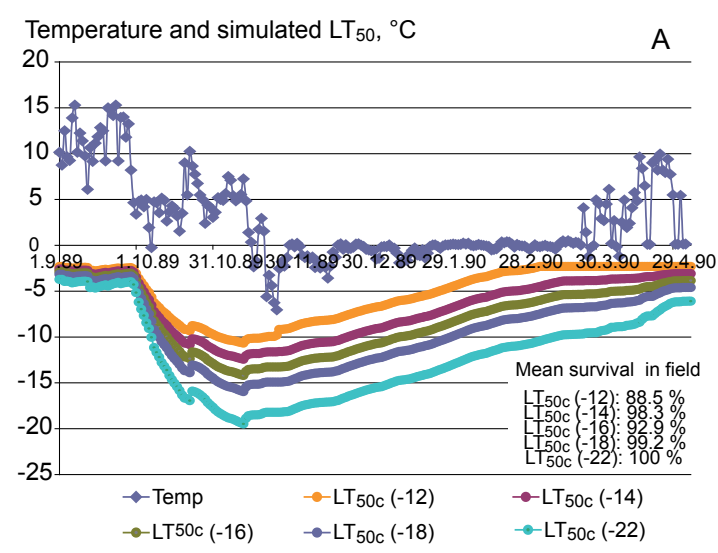

Sotkamo 1989/90

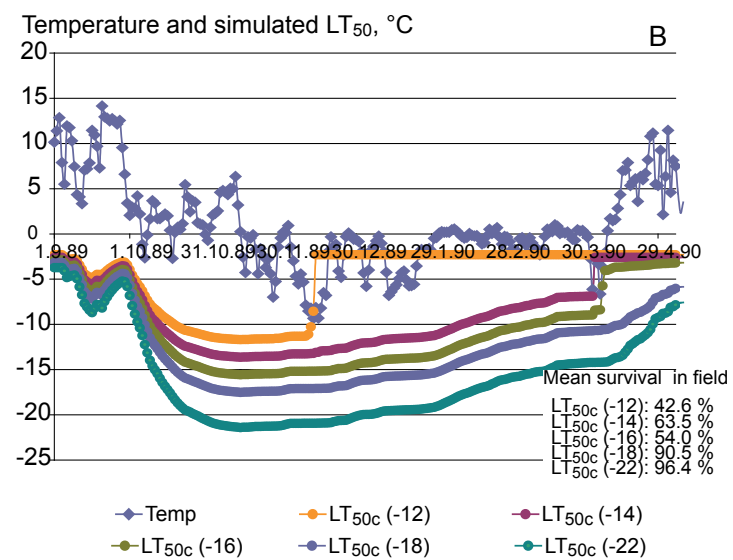

Fig. 3. For two locations: simulated courses of $\mathrm{LT}_{50}$, estimated soil surface temperature, and recorded mean survival in field of five cultivar classes with levels of maximum attainable frost tolerance ranging from -12 to $-22^{\circ} \mathrm{C}$.

be explained by the fact that FROSTOL estimates frost damage caused by the soil temperature regime only, while winter survival of different wheat cultivars in the Finnish field trials characterize a general ability to stand various types of winter stress. The frequency of fields and cultivar classes with high winter survival was, however, decreasing as the CSL increased (Fig. 5). As Figure 5 shows, the winter wheat did not seem to suffer any serious

\section{Mietoinen 1991/92}

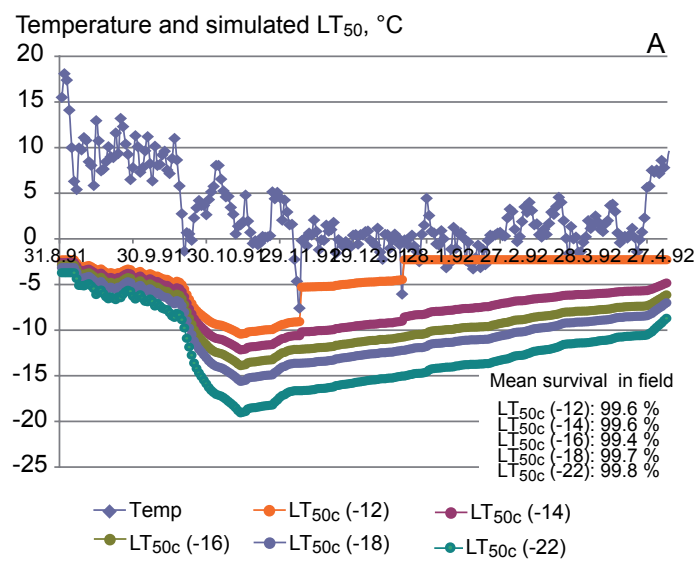

Temperature and simulated $\mathrm{LT}_{50},{ }^{\circ} \mathrm{C}$

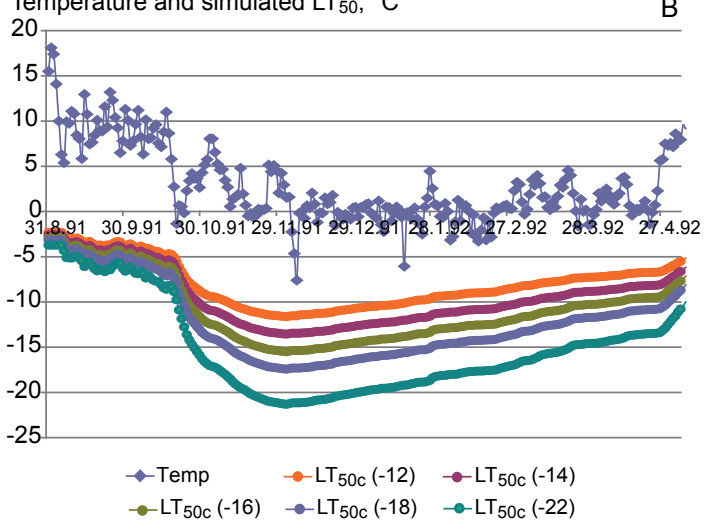

Fig. 4. At location Mietoinen 1991/92: simulated courses of $\mathrm{LT}_{50}$, estimated soil surface temperature, and recorded mean survival in field of five cultivar classes with levels of maximum attainable frost tolerance ranging from -12 to $-22{ }^{\circ} \mathrm{C}$. Plant hardening terminated and temperature threshold for dehardening lowered after vernalization saturation (A), and 21 days after vernalization saturation (B).

damage until the CSL increased to levels above eight, as calculated by eq. (2).

Not unexpected, large differences in rate of survival could be seen in the group of fields and cultivar classes which had been exposed to an intermediate stress level, with CSL ranging from eight to twelve (Fig. 5). When a calculated stress level based only on the soil temperature regime reaches 


\section{AGRICULTURAL AND FOOD SCIENCE}

Vol. 19 (2010): 184-192.

an intermediate level, the extent of occurrence of other stressful abiotic or biotic factors will be highly decisive for the survival rate.

For the three fields Jokioinen 1990/91, Laukaa 1989/90, and Sotkamo 1991/92, FROSTOL simulated less winter damages than what were actually recorded. A closer look at the weather data from these fields suggests that the plants might have experienced more stressful conditions in late winter or early spring than FROSTOL was able to account for. Periods with snow melting followed by low temperatures may have caused either an ice crust on the soil surface, or a more densely compacted snow cover, creating more anaerobic conditions to the plants. Alternate freezing and thawing of the upper soil layer, or desiccation due to irradiative heating of leaves while the roots were still in a frozen soil, are two other possible explanations for lower plant survival than estimated for these fields.

One of the stress factors in FROSTOL is caused by conditions where a largely unfrozen soil is covered by snow (RR). Snow cover is usually considered as beneficial, or even necessary, for winter survival, as it protects plants from being exposed to lethally low temperatures (Belanger et al. 2002). Results from Bergjord et al. (2008) do, however,

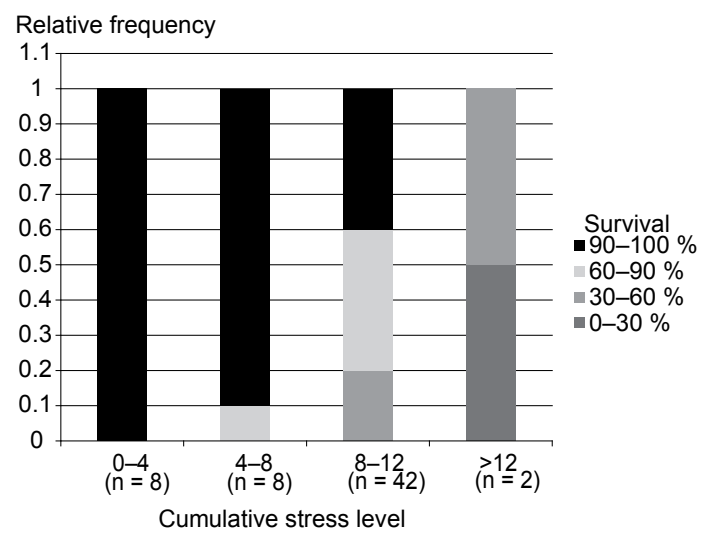

Fig. 5. Relative frequency of fields and cultivar classes with given levels of winter survival, as related to different cumulative stress levels (CSL) estimated by the FROSTOL model (eq. 2). The number of recordings (n) for each group of CSL varies and is given in parentheses below each column. indicate that a long-lasting snow cover might also have an exhausting effect, causing a reduction of the plants' frost tolerance, especially if the soil is unfrozen.

Most likely, a wet, dense snow cover will obstruct air flow and cause larger problems to the plants than a dry, loosely compacted snow cover. Gas exchange may be further obstructed if cycles of thawing and freezing cause the formation of ice layers in the snow as water from melting snow again is frozen. However, as the development of the RR equation was based on a limited number of empirical results from field trials (Bergjord et al. 2008), and knowledge of respiration stress during winter is scarce, the RR equation is yet not capable of differentiating between snow covers of differing densities when calculating stress level. Consequently, some over- or under-estimation of stress levels may have occurred. In Laukaa 1991/92 for instance, the high levels of RR calculated in FROSTOL seem to be an overestimate considering the absence of winter damage recorded in this field. Too high levels of RR may also be caused by overestimations of the soil surface temperature, suggesting a higher respiratory activity and hence more stressful conditions to the snow covered plants than what was actually the case.

In addition to the above mentioned probable explanations for the poor correlation, it should be mentioned that the two cultivar classes with $\mathrm{LT}_{50 \mathrm{c}}$ at $-18{ }^{\circ} \mathrm{C}$ and $-16{ }^{\circ} \mathrm{C}$ each includes one cultivar (Goertzen and Longbow, respectively, Table 1) which seems to be more susceptible to snow mould infections than the other cultivars of their classes (Hömmö 1994). In years and fields where snow mould infections were registered, their poorer survival hence affected both mean survival of their classes negatively, and consequently the correlation between simulated stress level in FROSTOL and recorded mean survival. Also, the lack of soil temperature recordings and the need for temperature estimation should be considered as a possible source of inaccuracy in these FROSTOL simulations. A small difference between actual and estimated temperature might in some cases not be of any importance. In other cases, when the temperature has been close to the plants' limits of frost 
Bergjord, A. K. et al., Modelling frost tolerance and winter survival in winter wheat

tolerance, it may make a great difference to the outcome of the simulation.

The results confirm that winter survival is the result of a combination of biotic and abiotic stress factors. As far as we know, no model currently exists that is able to account for all these various factors in winter survival simulations. The performed simulations seemed to correspond reasonably well to field observations when low temperature was the eventual cause of damage [e.g. Sotkamo 1989/90 (Fig. 3B)], and in fields where low temperature incidents during winter or spring did not cause any winter damage [e.g. Anjalankoski 1989/90 (Fig. 3A), Mietoinen 1991/92 with delayed generative induction (Fig. 4B)]. However, as FROSTOL at present only accounts for low temperature damages, it would not be realistic to expect the model to give accurate predictions of the extent of winter damage in all the presented fields and years. Still, it may provide useful information on the probabilities of having winter damage, as shown in Figure 5, and FROSTOL may hence be seen as a first step towards a model of winter survival in winter wheat under Nordic conditions. To improve the model's applicability, FROSTOL should be further developed to include modules simulating effects of snow moulds and of snow and ice cover densities on plant survival as well.

Acknowledgements. Technical assistance from Lasse Weiseth, estimation of soil surface temperatures by Stig Morten Thorsen, and valuable advice and support from Dr. Anne Kjersti Bakken are greatly appreciated. We also acknowledge the efforts of Dr. Leena Maarit Hömmö who has eased our work by compiling and evaluating the Finnish cultivar trials applied. The work was supported by The Norwegian Institute for Agricultural and Environmental Research, and by the Research Council of Norway.

\section{References}

Andrews, C.J. \& Pomeroy, M.K. 1979. Toxicity of anaerobic metabolites accumulating in winter wheat seedlings during ice encasement. Plant Physiology 64: 120-125.

Belanger, G., Rochette, P., Castonguay, Y., Bootsma, A., Mongrain, D. \& Ryan, D.A.J. 2002. Climate change and winter survival of perennial forage crops in eastern Can- ada. Agronomy Journal 94: 1120-1130.

Bergjord, A.K., Bakken, A.K. \& Skjelvåg, A.O. 2009. The relationship between frost tolerance and generative induction in winter wheat (Triticum aestivum L.) under field conditions. Canadian Journal of Plant Science. 89: 1031-1039.

Bergjord, A.K., Bonesmo, H. \& Skjelvåg, A.O. 2008. Modelling the course of frost tolerance in winter wheat I: Model development. European Journal of Agronomy 28: 321-330.

Danyluk, J., Kane, N.A., Breton, G., Limin, A.E., Fowler, D.B. \& Sarhan, F. 2003. TaVRT-1, a putative transcription factor associated with vegetative to reproductive transition in cereals. Plant Physiology 132: 1849-1860.

Fowler, D.B., Chauvin, L.P., Limin, A.E. \& Sarhan, F. 1996a. The regulatory role of vernalization in the expression of low-temperature-induced genes in wheat and rye. Theoretical and Applied Genetics 93: 554-559.

Fowler, D.B., Limin, A.E., Wang, S.Y. \& Ward, R.W. 1996 b. Relationship between low-temperature tolerance and vernalization response in wheat and rye. Canadian Journal of Plant Science 76: 37-42.

Gudleifsson, B.E. 1997. Survival and metabolite accumulation by seedlings and mature plants of timothy grass during ice encasement. Annals of Botany 79: 93-96.

Hömmö, L.M. 1994. Resistance of winter cereals to various winter stress factors - inter- and intraspecific variation and the role of cold acclimation. Doctoral Thesis published in: Agricultural Science in Finland 3, Supplement No. 1.

Jamieson, P.D., Semenov, M.A., Brooking, I.R. \& Francis, G.S. 1998. Sirius: a mechanistic model of wheat response to environmental variation. European Journal of Agronomy 8: 161-179.

Limin, A.E. \& Fowler, D.B. 2006. Low-temperature tolerance and genetic potential in wheat (Triticum aestivum L.): response to photoperiod, vernalization, and plant development. Planta 224: 360-366.

Mahfoozi, S., Limin, A.E. \& Fowler, D.B. 2001a. Developmental regulation of low-temperature tolerance in winter wheat. Annals of Botany 87: 751-757.

Mahfoozi, S., Limin, A.E. \& Fowler, D.B. 2001b. Influence of vernalization and photoperiod responses on cold hardiness in winter cereals. Crop Science 41: 1006-1011.

Pulli, S., Hjortsholm, K., Larsen, A., Gudleifsson, B.E., Larsson, S., Kristiansson, B., Hömmö, L.M., Tronsmo, A.M., Ruuth, P. \& Kristensson, C. 1996. Development and evaluation of laboratory testing methods for winterhardiness breeding. Publications - Nordic Gene Bank 32. 68 p.

Rickman, R.W., Waldman, S.E. \& Klepper, B. 1996. MODWht3: A development-driven wheat growth simulation. Agronomy Journal 88: 176-185.

Semenov, M.A. \& Porter, J.R. 1995. Climatic variability and the modeling of crop yields. Agricultural and Forest Meteorology 73: 265-283.

Slafer, G.A. \& Rawson, H.M. 1996. Responses to photoperiod change with phenophase and temperature during wheat development. Field Crops Research 46: 1-13.

Thorsen, S.M. \& Haugen, L.E. 2007. Development of the SnowFrost model for the simulation of snow fall and soil frost. Bioforsk FOKUS 2 (9). 23 p. 